\title{
Solar Desalination Using Fresnel Lens as Concentrated Solar Power Device: An Experimental Study in Tropical Climate
}

\author{
Wing Sum Choong, Zhi Yong Ho and Rubina Bahar* \\ Department of Mechanical Engineering and Materials Engineering, Lee Kong Chian Faculty of Engineering and Science, Universiti
} Tunku Abdul Rahman (UTAR), Cheras, Malaysia

Solar desalination is a renewable energy-driven method that produces freshwater from saline/brackish water. Conventional solar desalination units are equipped with an inclined transparent condensing plate placed over a feedwater basin containing saline water. The process is limited to a small quantity of production because of scattered solar irradiation and the unavailability of solar heat due to intermittent cloudy weather. In this study, a Fresnel lens has been used to concentrate solar energy onto a spot to increase the local

OPEN ACCESS

Edited by:

Agus P. Sasmito,

McGill University, Canada

Reviewed by:

A.E. Kabeel,

Tanta University, Egypt

Godwin Norense

Osarumwense Asemota, University of Rwanda, Rwanda

*Correspondence: Rubina Bahar

rubina@utar.edu.my

Specialty section: This article was submitted to

Sustainable Energy

Systems and Policies,

a section of the journal

Frontiers in Energy Research

Received: 25 May 2020 Accepted: 10 September 2020 Published: 22 October 2020

Citation:

Choong WS, Ho ZY and Bahar R (2020) Solar Desalination Using Fresnel Lens as Concentrated Solar Power Device: An Experimental Study in

Tropical Climate.

Front. Energy Res. 8:565542. doi: 10.3389/fenrg.2020.565542 temperature of feedwater and the evaporation rate. Flat Fresnel lenses on a double sloped passive solar still were used, where the focal points were adjusted to fall directly on the feedwater. The experiments were conducted for two different geometries and alongside the comparison between the conventional and the modified solar still; the number of Fresnel lenses was also varied. Saline solution with a concentration of 20,000 ppm was used as the feedwater. The research is aimed to be implemented for producing freshwater in the natural weather conditions of Malaysia. It was found that using two Fresnel lenses instead of a single large one gives a boost to the production of freshwater per unit solar irradiation by $39 \%$. The produced water has a total dissolved solids (TDS) value of $37 \mathrm{ppm}$, which is well within the drinking water standard range according to the World Health Organization.

Keywords: solar energy, solar desalination, solar still, concentrated solar power, Fresnel lens

\section{INTRODUCTION}

Solar desalination is the process that involves evaporation of a saline solution utilizing solar power, either directly or indirectly, followed by condensation of the generated vapor. In other words, solar distillation is a combination of humidification and dehumidification within a solar energy-driven setup (Belessiotis et al., 2016). This process is described as similar to a naturally occurring hydrological cycle, where the formation of the vapors from surface of liquids gets transported by wind to buildup and precipitate, and in the case of solar stills, vapors condensate on the colder surfaces inside the still (Lal et al., 2017). Conventional solar stills are basic devices that use the concept of a greenhouse by trapping heat during solar exposure and in turn, heats the stored feedwater within the device and increases its evaporation rate. Solar irradiation enters the still through a transparent cover underneath which the feedwater is stored. Upon striking the basin, the radiation is mostly absorbed by the basin. From the heated surface, infra-red electromagnetic waves 
are emitted and get trapped by the transparent cover, giving rise to the temperature within the system (Kumar and Tiwari, 2011). Solar stills can be a viable solution to produce drinking water in rural areas that lack fossil fuel/electric energy sources. However, the water quantity obtained from solar stills is not as high as its quality (Sharon and Reddy, 2015). The most affecting parameters on the still productivity and efficiency include the location, available solar intensity, ambient temperature, material and thickness of the glass cover, water depth in the basin, and the wind velocity (Al-harahsheh et al., 2018).

The geometrical dimension of a solar still plays an important role in the efficiency of the system. A direct correlation between still height, length, width, and distillate production was tested on conventional single slope solar still (Feilizadeh et al., 2017). The height of the basin wall was found to have a negative relationship with production, however, wider still produced higher yield due to the general increase in solar irradiance (SI) area, up to an optimum ratio of width over the length of $0.15(W / L=0.15)$. The effect of the tilt angle of the inclined cover plate was also studied. The tilt angle of the cover plate should be approximated to the latitude of location and the basin water depth was suggested to have a negative relationship with production (Selvaraj and Natarajan, 2018). In other words, lower water depth would give a higher yield of distillate. A linear decrement in productivity was found with increasing water depth (Akash et al., 2000). In the case of distillate production, glass cover gave the highest yield among other materials, compared to plastic sheet and Polyethylene terephthalate. An 18\% reduction in yield was reported when plastic is used instead of glass (Bhardwaj et al., 2013). Although having a superior yield compared to other materials, it was emphasized by Bhardwaj et al. (2013) that the negative characteristics of glass, such as brittleness, heavyweight, and higher maintenance cost make plastic a more suitable candidate for low cost, portable builds. Also in another study (Pollet and Pieters, 2000), the cover thickness showed a negative relationship to the transmittance of the cover, hence affecting the yield of the still.

Besides these factors, a lower intensity of solar irradiation is also a major cause for limited production. To increase the local temperature by focusing solar irradiation has been practiced through solar concentrators. These devices have been categorized as concentrated solar power (CSP) devices. Major solar concentrator types in the form of parabolic dishes and their trough variant were tested in Yadav and Yadav (2004), Chaouchi et al. (2007), Gorjian et al. (2014)'s study and reviewed by Dsilva Winfred Rufuss et al. (2016). Yet, less focus was given to Fresnel lens solar concentrator especially for solar desalination, even lesser for the radial variant, which is described in Gorjian et al. (2014).

This research aims to study the effectiveness of Fresnel lens in solar still applications and its viability as an additional equipment for the small-scale usage. Fresnel lens generally has a smaller footprint as compared to the more popular parabolic reflectors or convex lenses. A thin sheet of Fresnel lens can perform similarly as whole convex lenses or parabolic dishes; with little to no penalty to thickness when a smaller focal length is required. In this sense, Fresnel lens is also a better option when comparing the mobility and weight with that of other concentrators. The lenses are made from acrylic, therefore, it is lightweight and fabrication of the still is quite simple when the Fresnel lens is directly attached to the inclined lid.

In a study by Soni et al. (2019), it was concluded that a Fresnel lens is more suitable to be applied for solar power concentration in water heating application in the region between $15^{\circ} \mathrm{N}$ and $40^{\circ} \mathrm{S}$ with Minimum Direct Normal Irradiation (DNI) of $1.9 \mathrm{~kW} \mathrm{~h} / \mathrm{m}^{2}$ / yr and occasionally at higher latitudes.

The work presented here has been conducted in Malaysia that is located at $3.14^{\circ} \mathrm{N}$, with an average DNI value of around $800^{\circ} \mathrm{kW} \mathrm{h} / \mathrm{m}^{2} / \mathrm{yr}$ (Solargis, 2019). With this data, there is a need to investigate the overall effect of associating Fresnel lens and observe if there is any improvement compared to a conventional solar still. There is a research gap of applying CSP in solar desalination in Malaysia, although the nation is making rapid progress with photovoltaic (TENAGA, 2019). With climate change, freshwater scarcity is slowly seeping into the region with longer dry spells across peninsular Malaysia. Installation of a Reverse Osmosis water desalination plant is Sarawak (News Report) reflects the necessity of seawater desalination for the population in the bay areas. Recently there has been a research shift toward freshwater production by harnessing Malaysia's solar energy potentials (Abujazar et al., 2018; Hakim et al., 2018; Rafiei et al., 2019) pertaining to the need for drinking water produced sustainably; especially for the underprivileged population in the bay areas.

This study targets an initial investigation of the performance of Fresnel lenses as a solar concentrators for solar desalination in the persistent tropical weather of Malaysia. In this study, a solar still is equipped with flat radial Fresnel lenses to concentrate solar irradiation onto a single point in the saline water basin in the natural environment. As the data were taken in natural environment, the effect of changing weather patterns was minimized by the practice of normalizing the produced water to solar irradiation.

The flat radial Fresnel lens used in this study were chosen instead of the linear Fresnel lens due to its higher achievable temperature at its focal point. Comparisons between the performance of conventional solar stills and a Fresnel-lensequipped solar still were done by evaluating the hourly saline water temperature differences, internal and external solar still temperature differences, SI and distillate yield. The tests were conducted for two different design solar stills, to investigate the effect of a single Fresnel lens and multiple Fresnel lenses. The target for this research is to find the optimum conditions for Fresnel-lens-coupled solar still operation, together with investigating the viability and effectiveness of Fresnel lens application in solar still application.

\section{MATERIALS AND METHODS}

\section{Working Principle of the Solar Still}

Solar still is among the simplest form of solar desalination processes which consists of a basin containing saline/brackish water. The basin is covered with an inclined glass/transparent lid 


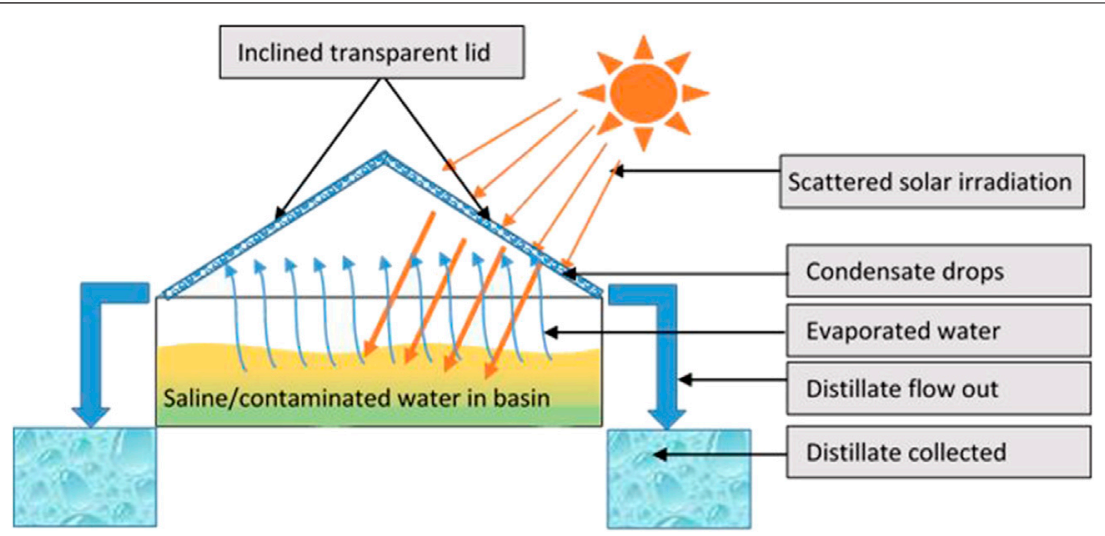

FIGURE 1 | Working Principle of a double-sloped solar still.

through which the solar heat enters and generates vapor from the contaminated water due to the partial pressure difference between the basin and the glass lid. The generated vapor is condensed on the inner side of the inclined glass/transparent lid and collected as the distillate. The transparent lid acts as the greenhouse to trap the heat inside the still. Figure 1 below shows the process for a simple solar still with a double slope. The double slope has been selected in the design to optimize the availability of solar irradiation throughout the day; without much necessity to rotate according to the Sun's travel path in the sky.

\section{Materials Selection}

This study aims to benefit people with resource scarcity in rural or coastal regions where access to clean water is limited. Therefore, the selection of cheaper material and easy design have been given priority during fabrication of the setup. Wood has been used as the outer still body material for its high workability and high thermal insulation property. Proper sealing has been provided using silicone sealant to prevent vapor from escaping the system. The basin has been made out of stainless steel. Material for the transparent cover was also decided to be of clear polycarbonate sheets instead of the conventional glass cover. While glass cover provides higher condensation performance, it was not considered in this case for brittleness and lower workability.

As mentioned by (Selvaraj and Natarajan (2018), insulation contributes largely to retaining heat within the solar still and increased productivity. Polystyrene was used to insulate the gap between the bottom of the metal basin and the wooden solar still frame to reduce thermal dissipation through the bottom of the solar still.

In the selection between linear and radial Fresnel lens, the different focusing profile of both types of lenses is the key point. For the linear Fresnel lens, the flat surfaces within the lens are aligned parallel to each other, with one more slanted than the other from inward to outward, creating a series of focusing surfaces to a central axis, at a distance to the lens. For the radial Fresnel lens, the ringshaped focusing surfaces slant to face a center point, with each ring placed concentric to each other. It has been found from a recent study (Huang et al., 2017) that the radial Fresnel lens can achieve a sunlight concentration ratio 3.9 times higher than that of the linear lens with a much smaller receiving area. Comparing the construction and focusing profile of both types of Fresnel lenses, the selected radial Fresnel lens which provides a pointfocus profile enables solar irradiation to be focused onto one spot instead of a line, significantly heating up elements on the focal point (Xie et al., 2011). The Fresnel lenses used in this experiment were made of polymethyl methacrylate (PMMA) (Acrylic).

\section{Experimental Setup and Variables}

Two different design setups with different aspect ratios were used with and without Fresnel lenses. They are categorized as:

i) Solar still without Fresnel lens (Model A-0 and Model B-0). ii) Solar still with Fresnel lens (Model A-F and Model B-F).

A double sloped passive solar still (Model-A) with a basin size of $500 \times 500 \times 100 \mathrm{~mm}$ was constructed. Figure $2 \mathrm{~A}$ is Model A without any Fresnel lens (termed as Model A-0). Model A equipped with a single Fresnel lens (Model A-F) is seen in Figure 2B. Model A has a Length/Width $(L / W)$ ratio of 1.0 and Model B has an $L / W$ ratio of 2.0. By estimating from the data of (Feilizadeh et al. 2017)'s study, around 10\% increase in productivity can be recorded when increasing from $L / W=1$ to $L / W=2$.

Another solar still (Model-B) with a wider aperture to solar irradiation was built to accommodate multiple Fresnel lenses. The basin size for this model is $700 \times 350 \times 100 \mathrm{~mm}$. This model has been tested with no Fresnel lens (Model B-0) and with the addition of two Fresnel lenses on the slope (Model B-F). The two arrangements of Model B are seen in Figures 2C,D respectively. A frame was constructed to hold the Fresnel lenses parallel to the inclination angle of the top covers, as seen in Figures 2B,D, whereby the focal points of the lenses fall onto the feedwater stored in the stainless-steel basin during solar irradiation period. Table 1 summarizes the structure and materials for these four models.

To conduct the experiments, the setup was installed at a location where solar irradiation was not blocked within the 


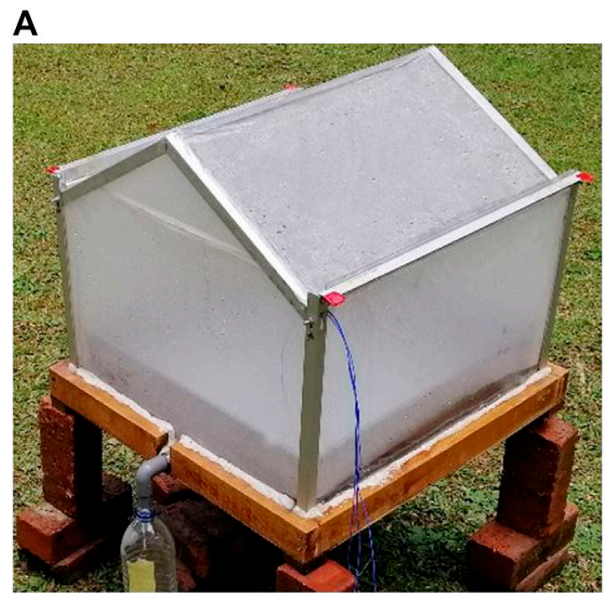

C

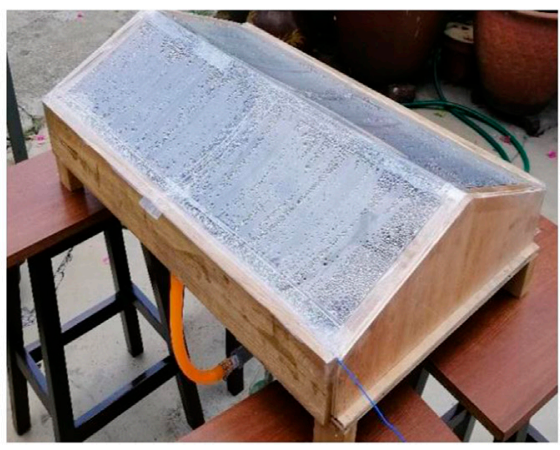

B

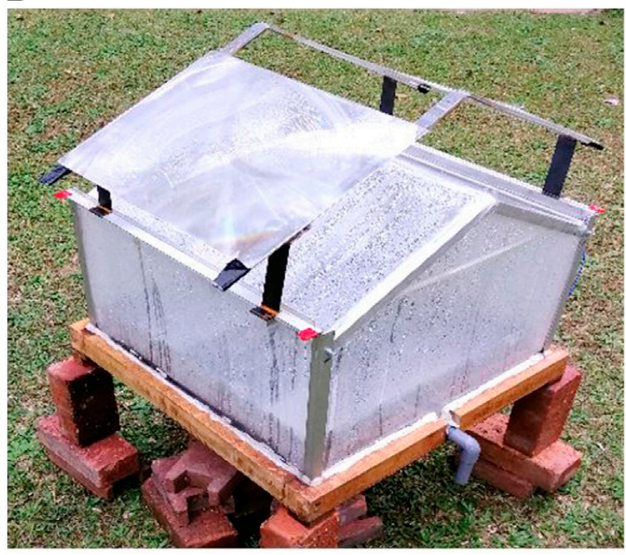

D

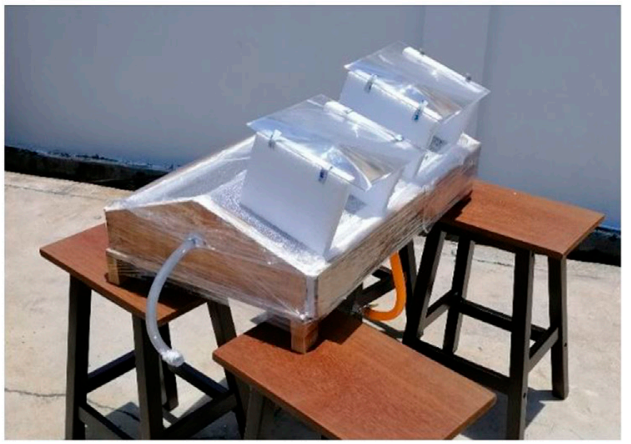

FIGURE 2 | (A)Solar still setup with no Fresnel lens (Model A-0). (B) Solar still with single Fresnel lens (Model A-F). (C) Wider Solar still with no Fresnel lens (Model B-0). (D) Wider solar still with multiple Fresnel lenses (Model B-F).

TABLE 1 | Design and materials specification of the four models.

\begin{tabular}{|c|c|c|c|c|}
\hline & Model A-0 & Model A-F & Model B-0 & Model B-F \\
\hline Basin size (mm) & $500 \times 500 \times 100$ & $500 \times 500 \times 100$ & $700 \times 350 \times 100$ & $700 \times 350 \times 100$ \\
\hline Basin material & SAE 304 & SAE 304 & ASTM A1008 & ASTM A1008 \\
\hline No. of Fresnel lens & 0 & 1 & 0 & 2 \\
\hline Size of Fresnel lens (mm) & - & $400 \times 300 \times 2$ & - & $240 \times 240 \times 2$ \\
\hline Focal point length of Fresnel lens (mm) & - & 600.0 & - & 300.0 \\
\hline Transparent cover & Cast acrylic (AA) & Cast acrylic (AA) & Cast acrylic (AA) & Cast acrylic (AA) \\
\hline Angle of inclination for transparent cover $\left({ }^{\circ}\right)$ & 30.0 & 30.0 & 20.0 & 20.0 \\
\hline Feedwater salinity (ppm) & $20,000.0$ & $20,000.0$ & $20,000.0$ & $20,000.0$ \\
\hline
\end{tabular}

duration of the experiment. Saline water solution with $20,000 \mathrm{ppm}$ concentration was fed to each model. The solar still was lifted from the ground using bricks to accommodate for the height of the measuring bottle. As shown in Figure 2A, three separate thermocouple channels wires (in blue) were inserted into the still. One of the thermocouple wires was immersed into the saline water and was made sure not to be in contact with the basin. The second wire was allowed to hang within the solar still above the basin, but not in contact with any other components. This is to record the internal temperature of the solar still. These thermocouple wires were made sure to be sealed along with the whole solar still as to not cause leakage at the inserts to the still. The third was attached to the basin surface and along the path where the focal point of the Fresnel lens passed through. This is to measure the temperature of the focusing spot. While the total energy entering the system is said to be equal with and without the solar concentrator due to the area receiving solar energy is equal for both cases, theoretically, the use of solar concentrator could raise the local temperature of the focal point significantly to induce more evaporation, thus increased vapor pressure within the still and resulting in higher condensation rate and more distillate yield. 

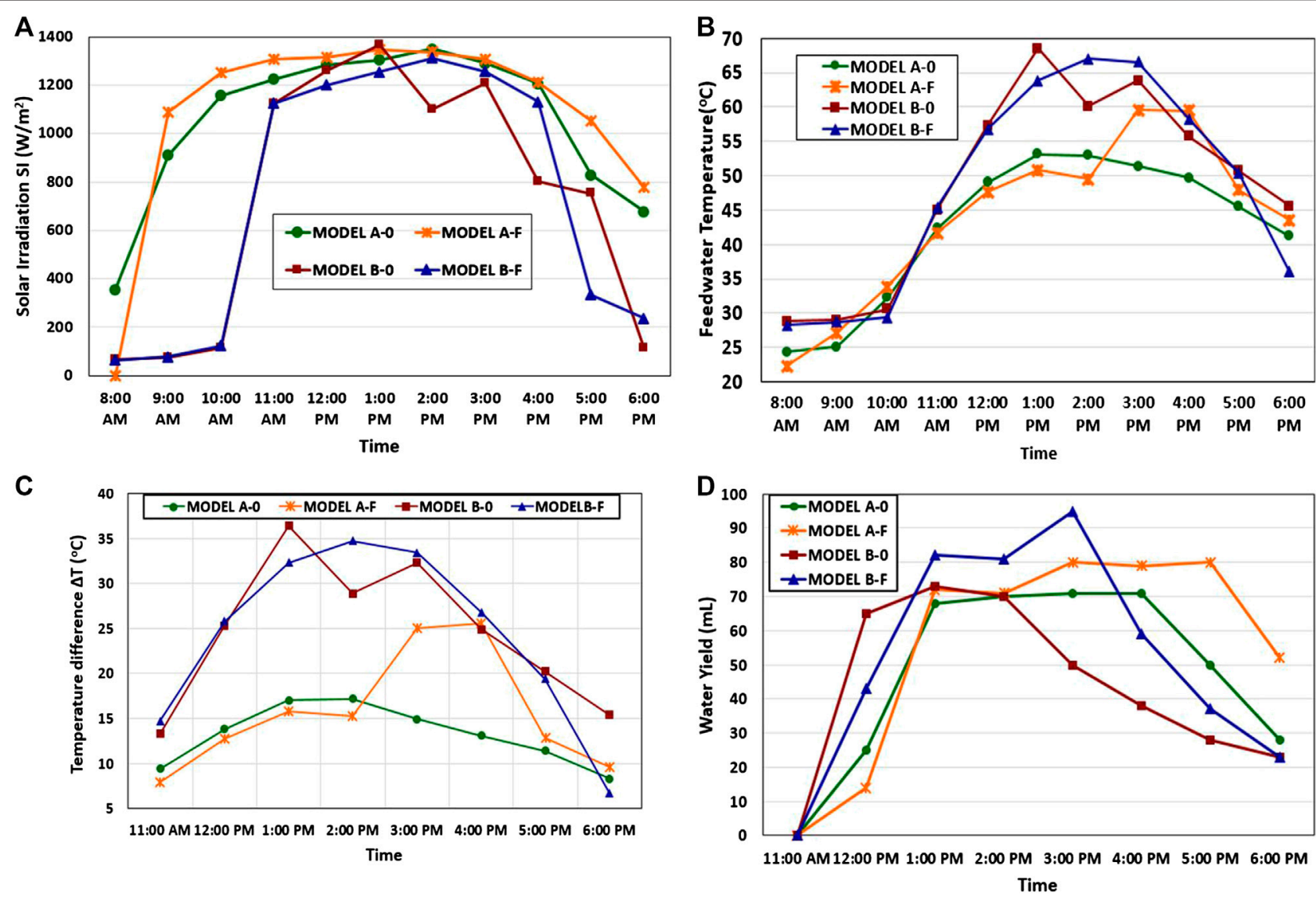

FIGURE 3 | (A) Hourly solar irradiation pattern. (B) Hourly feedwater temperature. (C) Hourly temperature difference between feedwater and ambient. (D) Hourly water production.

The SI was experimentally measured using SM206 High Precision Solar Power Meter by aligning the solar power meter perpendicular to the incoming SI on the transparent cover. Temperatures were recorded hourly along with the solar irradiation. The distillate levels were also measured using a weighing scale on an hourly basis. Experiments were conducted in Sungai Long, Selangor, Malaysia in March 2019. The average TDS value of the distillate was measured with a TDS EC Tester. The value was averaged at $37 \mathrm{ppm}$, which is well below the WHO drinking water standard of $500 \mathrm{ppm}$.

\section{RESULTS AND DISCUSSIONS}

\section{Solar Irradiation (SI) and its Effect on Temperature for Different Setups}

In this section, the performance of the solar still under variable operating parameters like solar irradiation and temperature has been discussed.

The graphs and calculations have been prepared based on SI or the insolation. Although the sensitivity study conducted by Chhatbar (2011) showed that DNI is the parameter with the highest influence on the energy yield of CSP plants, however, the solar power meter provided the data for SI only and it was the base for calculations of total productivity.

Furthermore, the major objective to conduct this study is to analyze the performance of a passive solar still equipped with Fresnel lens experimentally in the tropical climate of Malaysia, therefore calculations of DNI has not been considered in this study.

Figures 3A,B represent the solar irradiation and feedwater temperature for the four models considered in this study. The experiments were conducted on different days and it can be seen that the patterns of received solar irradiation varied on these days. Figure 3A shows the hourly solar irradiation between 8.00 am and $6.00 \mathrm{pm}$. For Models A-0 and A-F, the solar irradiation exposure time and intensity were and almost similar. While for Models B-0 and $\mathrm{B}-\mathrm{F}$, the exposure times are comparable, however, model B-0 faced a drop in solar irradiation intensity around $2.00 \mathrm{pm}$, due to the appearance of cloud at that time. This uncertainty is commonly associated with all renewable energy resources. And therefore, necessary normalization of data to observe the productivity from different setups was practiced which is described in "Overall Performance Using Fresnel Lens"section.

In Figure 3B, the effect of the solar irradiation on the feedwater temperature for each model is shown. It can be seen 


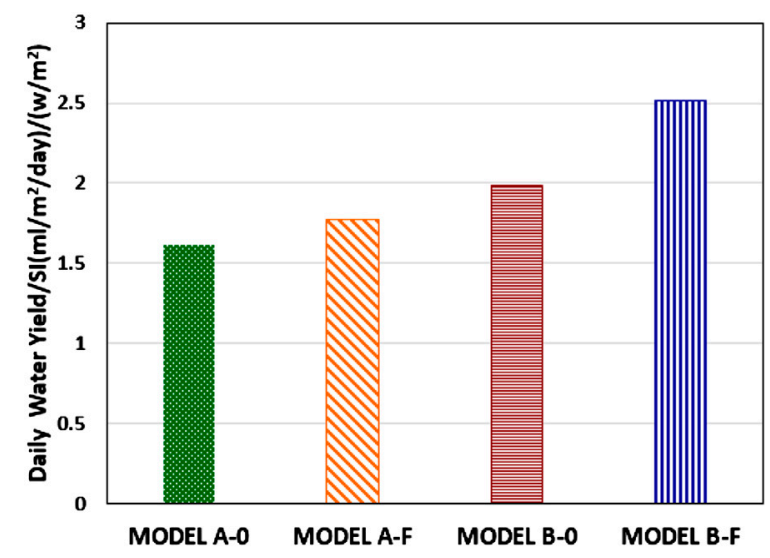

FIGURE 4 | Daily water yield per average solar irradiation (SI).

for Model A-0 and Model A-F that although they received an equivalent amount of solar irradiation, the feedwater temperature in the afternoon for Model A-F had a drastic increase in feedwater temperature. For the feedwater temperature of Model B-0 and Model B-F, Model B-F maintained a steady and slightly higher value compared to that of Model B-0. However, a sudden drop in temperature is seen as expected around $2.00 \mathrm{pm}$, which is caused by the sudden drop in solar irradiation for Model B-0 due to rain occurring at that instance.

\section{Temperature Difference Between Feedwater and Ambient and its Effect on Hourly Water Production}

Figures 3C,D are the hourly temperature differences and the water yield from each of the four models. The temperature difference $(\Delta \mathrm{T})$ is calculated between the feedwater and ambient temperature as that is the major potential difference for evaporation to occur. The more this difference, the more should be the partial pressure difference between the feedwater and the ambient, which would cause more evaporation. From Figure 3C, it is clear that Model B-0 and Model B-F which inherently had a wider aperture to solar irradiation attained the higher $\Delta T$, compared to Model A-0 and Model A-F. It is seen from Figure 3D that both the Models equipped with Fresnel lens (A-F and B-F) tend to produce the highest water yield on an hourly basis compared to those without a Fresnel lens.

\section{Overall Performance Using Fresnel Lens}

In the previous sections "Solar Irradiation (SI) and its Effect on Temperature for Different Setups," and "Temperature Difference Between Feedwater and Ambient and its Effect on Hourly Water Production," the temperature and water yield have been discussed with respect to hourly solar irradiation. It has also been observed that the solar irradiation was not constant during the experiments conducted with four different arrangements. Therefore, it is needed to normalize the experimentally obtained data to reach a decision about the performance of Fresnel lenses as a solar concentrator.

Along with the addition of Fresnel lenses, the overall performance per square meter of the area has been investigated in this section.

First, the average water yield per solar irradiation (SI) was calculated for the four models for solar exposure hours. The average solar irradiation for Models A-0 and A-F were 1,053 and $1,165 \mathrm{~W} / \mathrm{m}^{2}$ respectively, while for Models B-0 and B-F were 718 and $737 \mathrm{~W} / \mathrm{m}^{2}$, respectively. Based on these data, Figure 4 shows the comparison of water yield flux per day per average solar irradiation. It is seen that in terms of the daily water yield flux against SI, a $9.7 \%$ improvement was obtained with the application of the Fresnel lens between Model A- 0 and Model A-F. A significant improvement of 26.4\% was observed between the averages Water Yield against SI for Model B-F, compared to Model B-0, as seen in the figure.

A further comparison was conducted between Model A-F and Model B-F to observe the total water production per unit total solar irradiation and how the number of Fresnel lens influences the water production. Figure 5A shows the summarized result of total water yield over total SI for the four models. The Model B-F produced the highest amount of distillate per total solar irradiation. Compared to model A-F, with a single Fresnel lens, the Model B-F with two Fresnel lenses produced about $39 \%$ more water per total SI for the day.

The effect of total solar exposure area of the feedwater basin for these models was also compared; as seen in Figure 5B, the total water yield per total SI was again calculated per unit area of the feedwater basin. It has been found that the total water yield per unit area was highest for Model B-F, which had a solar exposure area of $700 \times 350 \mathrm{~mm}^{2}$, with an $L / W$ ratio of 2.0 compared to Model A (0 and F) which had an area of $500 \times 500 \mathrm{~mm}^{2}$, with an $L / W$ ratio of 1.0. When compared between Models A and B, it was seen that Model B had an increase in production by $22 \%$, while with added Fresnel lens, the performance of Model B was $41.8 \%$ higher.

\section{CONCLUSIONS}

This study was conducted as an initial investigation to observe the applicability of the Flat Fresnel lens as a cheap CSP device, which is conducted through experiments on different geometry solar stills varying the number of lenses. The study revealed that incorporating the Fresnel lens in tropical weather can enhance the overall production of distillate from a solar still, although the location does not receive strong DNI. This study has opened up the possibility of further exploration in this field through more vigorous experiments. The findings can be summarized as:

1. Fresnel lens increases the total production from a solar still. The addition of Fresnel lenses increased the average and total production rate for different geometry solar stills.

2. Using multiple Fresnel lenses instead of a single one provides multiple hotspots and causes more evaporation of feedwater, thus leading to higher total production per total solar irradiation by $39 \%$. 

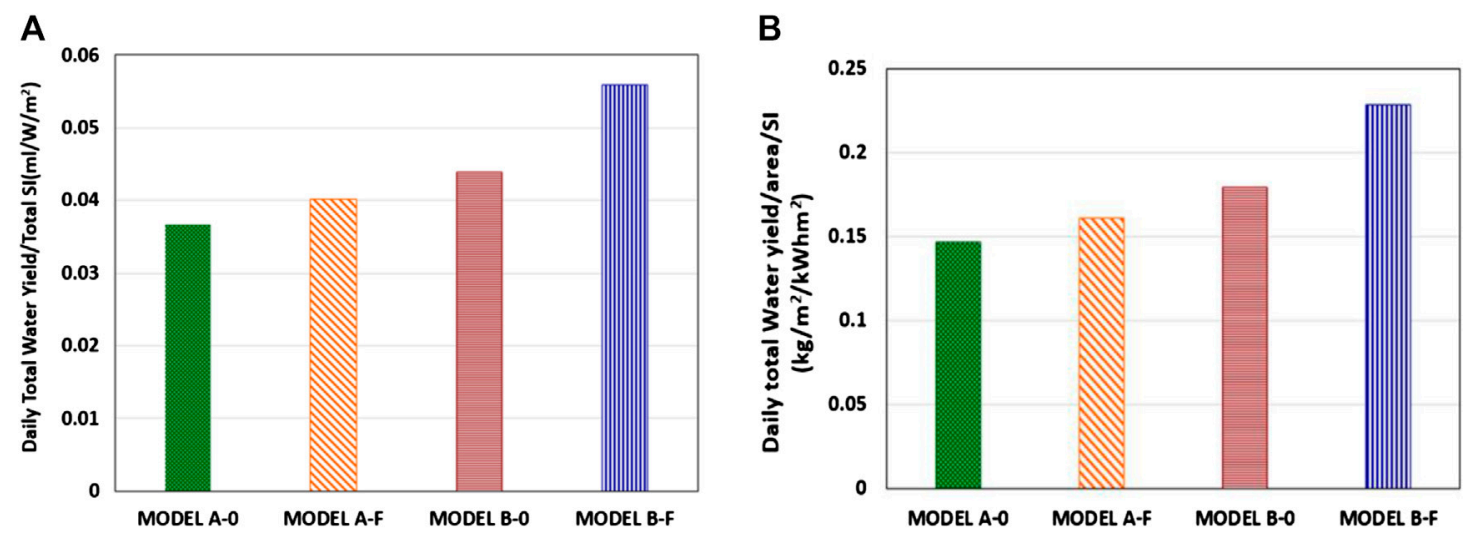

FIGURE 5 | (A) The total water yield over total SI. (B) The total water yield per unit area over total SI.

3. The increased length/width ratio caused significant improvement in production for all models, with the highest performance improvement of $41.8 \%$ for the Fresnel lens associated model.

\section{DATA AVAILABILITY STATEMENT}

The raw data supporting the conclusions of this article will be made available by the authors, without undue reservation.

\section{AUTHOR CONTRIBUTIONS}

WSC: (Methodology, Investigation, Validation, Formal analysis, Data Curation, Writing - Original Draft). ZYH: Conceptualization, Formal analysis, Project administration. RB: Formal analysis, Validation, Data Curation, Resources, Writing Review and Editing, Supervision, Project administration, Funding acquisition.

\section{REFERENCES}

Abujazar, M. S. S., Fatihah, S., Lotfy, E. R., Kabeel, A. E., and Sharil, S. (2018). Performance evaluation of inclined copper-stepped solar still in a wet tropical climate, Desalination 425, 94-103. doi:10.1016/j.desal.2017.10.022

Akash, B. A., Mohsen, M. S., and Nayfeh, W. (2000). Experimental study of the basin type solar still under local climate conditions. Energy Convers. Manag. 41 (9), 883-890. doi:10.1016/S0196-8904(99)00158-2

Al-harahsheh, M., Abu-Arabi, M., Mousa, H., and Alzghoul, Z. (2018). Solar desalination using solar still enhanced by external solar collector and PCM. Appl. Therm. Eng. 128, 1030-1040. doi:10.1016/j.applthermaleng. 2017.09.073

Belessiotis, V., Kalogirou, S., and Delyannis, E. (2016). Solar distillation-solar stills. Therm. Sol. Desalin. 85, 103, doi:10.1016/b978-0-12-809656-7.00003-9

Bhardwaj, R., ten Kortenaar, M. V., and Mudde, R. F. (2013). Influence of condensation surface on solar distillation, Desalination 326, 37. doi:10.1016/ j.desal.2013.07.006

Chaouchi, B., Zrelli, A., and Gabsi, S. (2007). Desalination of brackish water by means of a parabolic solar concentrator. Desalination 217, 118. doi:10.1016/j. desal.2007.02.009

Chhatbar, K. (2011). The influence of meteorological parameters on the energy yield of solar thermal plants. Conf. Conc. Sol.Power

\section{FUNDING}

The work has been conducted in Lee Kong Chian Faculty of Engineering and Science, Universiti Tunku Abdul Rahman and the study has been supported by Universiti Tunku Abdul Rahman (UTAR) internal Grant IPSR/RMC/UTARRF/2018C1/R01.

\section{ACKNOWLEDGMENTS}

This work has been funded by Universiti Tunku Abdul Rahman (UTAR)'s internal grant: "UTAR Research grant IPSR/RMC/ UTARRF/2018-C1/R01." Authors are grateful to Centre for Photonics and Advanced Materials Research for providing facilities and support.

Dsilva Winfred Rufuss, D., Iniyan, S., Suganthi, L., and Davies, P. A. (2016). Solar stills: a comprehensive review of designs, performance and material advances. Renew. Sustain. Energy Rev. 63, 464. doi:10.1016/j.rser.2016.05.068

Feilizadeh, M., Soltanieh, M., Karimi Estahbanati, M. R., Jafarpur, K., and Ashrafmansouri, S. S. (2017). Optimization of geometrical dimensions of single-slope basin-type solar stills. Desalination 424 159-168. doi:10.1016/ j.desal.2017.08.005

Gorjian, S., Ghobadian, S., Tavakkoli Hashjin, T., and Banakar, A. (2014). Experimental performance evaluation of a stand-alone point-focus parabolic solar still. Desalination 352 1-17. doi:10.1016/j.desal.2014.08.005

Hakim, A. B. A., Azni, M. E., Mupit, M., and Bakar, N. A. (2018). Development of solar desalination system from seawater by using basin solar energy. Mater Today: Proc. 5, 22137-22142. doi:10.1016/j.matpr.2018.07.081

Huang, R., Zhang, X., Ng, B. P., Kumar, A. S., and Liu, K. (2017). Roll-to-roll embossing of optical radial Fresnel lenses on polymer film for concentrator photovoltaics : a feasibility study. Int. J. Precis. Eng. Manuf.-Green Tech. 1-19. doi:10.1007/s40684-019-00166-6

Kumar, S., and Tiwari, G. N. (2011). Analytical expression for instantaneous energy efficiency of a shallow basin passive solar still. Int. J. Therm. Sci. 50, 2543. doi:10. 1016/j.ijthermalsci.2011.06.015

Lal, R. K., Yadav, S. V. P., Dwivedi, J. P., and Dwivedi, H. (2017). Comparative Performance evaluation of an active/passive solar Distillation system. Mater. Today: Proc. 4, 2822-2831. doi:10.1016/j.matpr.2017.02.162 
News Report (2013). The Choice, PM Najib Launches RM 60 Million Desalination Project in Sarawak.

Pollet, I. V., and Pieters, J. G. (2000). Condensation and radiation transmittance of greenhouse cladding materials, part 3: results for glass plates and plastic films. J. Agric. Eng. Res. 77 (4), 419-428. doi:10.1006/jaer.2000.0628

Rafiei, A., Alsagri, A. S., Mahadzir, S., Loni, R., Najafi, G., and Kasaeian, G. (2019). Thermal analysis of a hybrid solar desalination system using various shapes of cavity receiver: cubical, cylindrical, and hemispherical. Energy Convers. Manag. 198, 111861. doi:10.1016/j.enconman.2019.111861

Selvaraj, K., and Natarajan, A. (2018). Factors influencing the performance and productivity of solar stills-a review. Desalination 435, 181. doi:10.1016/j.desal. 2017.09.031

Sharon, H., and Reddy, K. S. (2015). A review of solar energy driven desalination technologies. Renew. Sustain. Energy Rev. 41, 1080-1118. doi:10.1016/j.rser.2014.09. 002

Solargis (2019). Solar resource maps of Malaysia, World bank glob. Sol. Atlas 2.0. Available at: https://solargis.com/maps-and-gis-data/download/malaysia.

Soni, V. K., Shrivastava, R. L., Untawale, S. P., and Shrivastava, K. (2019). Performance analysis and optimization of Fresnel lens concentrated solar water heater. J. Sol. Energy Eng. Trans. ASME. 141, doi:10.1115/1.4041846
TENAGA NASIONAL (2019). BERHAD, GO SOLAR WITH US NOW! Harness solar energy today for your better and brighter tomorrow.

Xie, W. T., Dai, Y. J., Wang, R. Z., and Sumathy, K. (2011). Concentrated solar energy applications using Fresnel lenses: a review. Renew. Sustain. Energy Rev. 15, 2588. doi:10.1016/j.rser.2011.03.031

Yadav, Y. P., and Yadav, S. K. (2004). Parametric studies on the transient performance of a high-temperaturesolar distillation system. Desalination 170, 251. doi:10.1016/j.desa1.2004.03.019

Conflict of Interest: The authors declare that the research was conducted in the absence of any commercial or financial relationships that could be construed as a potential conflict of interest.

Copyright $\odot 2020$ Choong, Ho and Bahar. This is an open-access article distributed under the terms of the Creative Commons Attribution License (CC BY). The use, distribution or reproduction in other forums is permitted, provided the original author(s) and the copyright owner(s) are credited and that the original publication in this journal is cited, in accordance with accepted academic practice. No use, distribution or reproduction is permitted which does not comply with these terms. 